\title{
Pharmacokinetics of furosemide in thoroughbred horses subjected to supramaximal treadmill exercise with and without controlled access to water
}

\author{
N. F. Villarino', C. M. Lopez ${ }^{2}$, R. A. Sams ${ }^{3}$ and W. M. Bayly ${ }^{2^{*}}$ (1)
}

\begin{abstract}
Background: The primary objective of this study was to assess the disposition of furosemide in Thoroughbred horses treated intravenously with $1 \mathrm{mg} / \mathrm{kg}$ of furosemide 4 and $24 \mathrm{~h}$ before supramaximal treadmill exercise without and with controlled access to water, respectively. Another objective was to determine whether furosemide was detectable in the plasma of horses after exposure to supramaximal treadmill exercise. Thoroughbred horses $(n=4-6)$ were administered single intravenous doses of $1 \mathrm{mg} / \mathrm{kg}$ of furosemide at 4 and $24 \mathrm{~h}$ before supramaximal exercise on a high-speed treadmill, with controlled and free access to water, respectively. Plasma furosemide concentrations were determined using liquid chromatography.
\end{abstract}

Results: Furosemide was detected in all the horses, regardless of whether they were treated $24 \mathrm{~h}$ or $4 \mathrm{~h}$ before excersice. In both treatment sequence groups of 2 horses, the concentration time profiles of furosemide during the

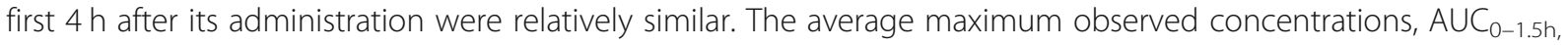
and $A \cup C_{0-3 h}$, of both groups of horses were not different $(p>0.05)$. There were no significant differences in systemic clearance based on the geometric mean (95\% confidence interval) $(409$ (347-482) $\mathrm{mL} / \mathrm{h} / \mathrm{kg}$ ) for $4 \mathrm{~h}$ and $320(177-580) \mathrm{mL} / \mathrm{h} / \mathrm{kg}$ ) for $24 \mathrm{~h}$ ) between horses that were exercised 4- and 24-h post-furosemide administration. The plasma concentration of furosemide in all the horses fell below the limit of quantification $(25 \mathrm{ng} / \mathrm{mL})$ within 12 $\mathrm{h}$ after drug administration. In the group treated $24 \mathrm{~h}$ before exercise, none of the horses had detectable furosemide at the time of supramaximal treadmill exercise. In the group treated $4 \mathrm{~h}$ before exercise, furosemide was detected $1 \mathrm{~h}$ before and $2 \mathrm{~h}$ after supramaximal treadmill exercise in $4 / 4$ and $3 / 4$ horses, respectively. The mean $\mathrm{AUC}_{3 \text {-last } \mathrm{h}}$ of both groups of horses were not different $(p>0.05)$.

Conclusions: Water restriction did not exert any apparent effect on the disposition of furosemide. It remains to be determined, however, whether the attained plasma concentration of furosemide in combination with other controlled water access protocols have any direct or indirect pharmacological effect that may affect the athletic performance of the horse.

Keywords: Diuretics, Controlled water intake, Exercise-induced pulmonary hemorrhage, Furosemide, Pharmacokinetics, Horses

\footnotetext{
* Correspondence: wmb@vetmed.wsu.edu

${ }^{2}$ Department of Veterinary Clinical Sciences, Washington State University, PO

Box 646610, Pullman, WA 99164-6610, USA

Full list of author information is available at the end of the article
}

(c) The Author(s). 2019 Open Access This article is distributed under the terms of the Creative Commons Attribution 4.0 International License (http://creativecommons.org/licenses/by/4.0/), which permits unrestricted use, distribution, and reproduction in any medium, provided you give appropriate credit to the original author(s) and the source, provide a link to the Creative Commons license, and indicate if changes were made. The Creative Commons Public Domain Dedication waiver (http://creativecommons.org/publicdomain/zero/1.0/) applies to the data made available in this article, unless otherwise stated. 


\section{Background}

Furosemide is a high-ceiling loop diuretic. In horses, its plasma concentration decreases rapidly following intravenous administration and this is reflected by its high clearance $(8.9-10.7 \mathrm{~mL} / \mathrm{min} / \mathrm{kg})$ in exercised horses [1] and short terminal half-life (2-4h) [2]. In horses, $50-60 \%$ of a furosemide dose is cleared renally, whereas the rest is conjugated to glucuronic acid in the liver or in the kidneys [3] and excreted in the urine. In healthy horses with free access to drinking water, at least $90 \%$ of the intravenous dose of furosemide is eliminated within $4 \mathrm{~h}$ following drug administration. The diuretic effect of furosemide is correlated with its plasma concentration. In fact, this drug produces a marked increase in the rate of urine formation between 15 and $30 \mathrm{~min}$ following its intramuscular or intravenous administration. However, no diuretic effect can be detected, $4 \mathrm{~h}$ after its administration [4].

Furosemide is administered approximately $4 \mathrm{~h}$ before racing in accordance with the rules of racing in the USA and numerous other countries in the Americas. Its use came to prominence in the late 1960s and early 1970s for its putative role in the prophylaxis of exercise-induced pulmonary hemorrhage (EIPH) [5-8]. EIPH is bleeding in the lungs that occurs in the majority of Thoroughbred and Standardbred racehorses subjected to strenuous exercise [9]. It has been suggested that furosemide attenuates the severity of EIPH by reducing pulmonary vascular pressures during strenuous exercise, although a mechanism by which the drug does this has yet to be identified.

At racetracks where the rules of racing allow its use, furosemide is administered intravenously to horses at a dose up to 0.5 or $1.0 \mathrm{mg} / \mathrm{kg}$ body weight, depending on the racing authority. However, national and international pressure has been growing to prohibit race day medication in order to avoid any potential beneficial effect of furosemide which might directly or indirectly alter the athletic performance of the horse, and the resultant negative public image of the sport that stems from this possibility [9]. Unfortunately, furosemide is the only pharmacologic treatment for EIPH that has been scientifically demonstrated to mitigate EIPH. Therefore, if race day administration of furosemide is prohibited, veterinarians may start administering furosemide to horses on the day before racing. Consequently, the pharmacokinetics of these dosage regimens when given this far before racing warrant investigation, particularly when the possible effects of strenuous exercise and pre-race management practices such as controlling access to water are considered.

Administration of furosemide is not the only management strategy used to prevent or reduce the severity of
EIPH in horses. Controlled intake of water before racing is also sometimes practiced in the belief that it helps lower blood pressure, and therefore prevents or decreases the severity of EIPH [10]. Although several studies have been carried out to assess plasma disposition of furosemide, the kinetics of this drug in horses subjected to a controlled intake of water for $24 \mathrm{~h}$ remains to be determined. In fact, in strenuously exercising horses, managed water intake and a marked contraction of the circulating plasma volume subsequent to furosemide administration [11] could alter the fate of furosemide. A decrease in the rate of elimination of the drug could result in an increase in its plasma concentrations and this in turn could prolong the overall pharmacological effect of the agent. It might also increase the likelihood of the drug being detected post-racing in jurisdictions in which the presence of any furosemide in a test sample collected from the horse is a punishable offence. Using an elegant experimental design, Knych and colleagues reported no significant differences in the volumes of distribution at steady-state or systemic clearances between horses that were exercised at 4 and $24 \mathrm{~h}$ following the iv administration of $250 \mathrm{mg} / \mathrm{kg}$ of furosemide with no access to water for $4 \mathrm{~h}$ before treadmill exercise [12]. It is unknown whether controlling or withholding water access for longer periods than $4 \mathrm{~h}$ would have any effect on the disposition of furosemide.

Prolonged submaximal exercise was not found to have any apparent effect on the disposition of furosemide during the first $2 \mathrm{~h}$ following drug administration [1]. However a brief period of intense exercise may reduce the systemic clearance of furosemide as a consequence of decreased renal [13, 14] or hepatic [3] blood flow during the short period of exercise, thus altering the disposition of drugs cleared by the kidneys and the liver $[15,16]$.

Considering the gaps in our current knowledge concerning the disposition of furosemide in racehorses, one objective of this study was to assess the disposition of this diuretic in the plasma of Thoroughbred horses treated intravenously with $1 \mathrm{mg} / \mathrm{kg}$ furosemide 4 and $24 \mathrm{~h}$ before supramaximal treadmill exercise, without and with controlled access to water, respectively (Objective 1). Another objective (Objective 2) was to determine whether furosemide was detectable in the plasma of horses after they were subjected to supramaximal treadmill exercise under these conditions.

\section{Results}

The administration of furosemide combined with controlled access to water and high intensity exercise protocols to fatigue had no negative impact on any of the horse health parameters investigated in this study. 
Objective 1: disposition of furosemide in the plasma of horses treated 4 and $24 \mathrm{~h}$ prior to supramaximal treadmill exercise

The individual treadmill speeds at which the horses galloped ranged from 12.3 to $14.2 \mathrm{~m} / \mathrm{s}$, with the duration of exercise at these speeds ranging from 85 to $120 \mathrm{~s}$. Furosemide was detected in all the horses, regardless of whether they were treated $24 \mathrm{~h}$ or $4 \mathrm{~h}$ before exercising (Table 1, Fig. 1). In both groups of horses, the plasma concentration of furosemide decreased at two apparent rates. Within the first $2 \mathrm{~h}$ following the administration of the drug, plasma concentrations decreased rapidly, whereas at a later time point the plasma concentration of furosemide decreased at a slower rate (Fig. 1).

In both treatment sequence groups of 2 horses, the concentration time profiles of furosemide during the first $4 \mathrm{~h}$ after its administration were relatively similar, as reflected by the overlapping of individual drug concentration vs. time profiles between 0 and $3 \mathrm{~h}$ after drug administration. In all horses, the maximum concentration was observed in the first sample collected $(0.1 \mathrm{~h})$ after drug administration. The average maximum observed concentrations, $\mathrm{AUC}_{0-1.5 \mathrm{~h}}$, and $\mathrm{AUC}_{0-3 \mathrm{~h}}$, of both groups of horses were not different $(p>0.05)$. For horse $\mathrm{D}$ in the $4 \mathrm{~h}$ pre-exercise treatment group, we do not report PK parameter estimates using compartmental analysis because there was not enough data for appropriate fitting of pharmacokinetic models. Thus, for this horse, we only report pharmacokinetic parameters estimated by non-compartmental analysis.

The plasma concentration of furosemide in all the horses fell below the limit of quantification $(25 \mathrm{ng} / \mathrm{mL})$ within $12 \mathrm{~h}$ after drug administration. In the group treated $24 \mathrm{~h}$ before exercise, none of the horses had detectable furosemide at the time of supramaximal treadmill exercise. In the group treated $4 \mathrm{~h}$ before exercise, furosemide was detected $1 \mathrm{~h}$ before and $2 \mathrm{~h}$ after supramaximal treadmill exercise in $4 / 4$ and $3 / 4$ horses, respectively. The pharmacokinetic parameters are presented in Table 2. The mean $\mathrm{AUC}_{3 \text {-last } \mathrm{h}}$ of both groups of horses were not different $(p>0.05)$.

\section{Objective 2 determination of the plasma concentration of furosemide $24 \mathrm{~h}$ after its administration}

Using the more sensitive analytical technique (LLOQ 1 $\mathrm{ng} / \mathrm{mL}$ ), furosemide was quantified in the plasma of all the horses $24 \mathrm{~h}$ after its administration. The results are presented in Table 3. A higher concentration of furosemide was obtained in the group of horses receiving a dose of 1 $\mathrm{mg} / \mathrm{kg}$. Within the group of horses treated with $1 \mathrm{mg} / \mathrm{kg}$ furosemide, the plasma concentration at $24 \mathrm{~h}$ after drug administration was numerically higher (but not significantly $p=0.4$ ) when the horses were subjected to the controlled water intake protocol than when they were allowed free access to water (mean $\pm \mathrm{SD}, 0.8 \pm 1.3$ and $0.44 \pm 0.72$, respectively). The tolerance limits for furosemide plasma concentration are presented in Table 3.

\section{Discussion}

This study reports the disposition of furosemide in racehorses exposed to supramaximal treadmill exercise either 24 or $4 \mathrm{~h}$ after furosemide administration of 0.5 and $1 \mathrm{mg} / \mathrm{kg}$ body weight with and without management of their pre-exercise water consumption. Furthermore, this study confirms that furosemide, at a dosage of 0.5 and 1 $\mathrm{mg} / \mathrm{kg}$ body weight, is still detectable $24 \mathrm{~h}$ post administration, if an appropriate LC-MS/MS method characterized by a LOQ $0.1 \mathrm{ng} / \mathrm{mL}$ is used.

Following the administration of $1 \mathrm{mg} / \mathrm{kg}$ body weight, the disposition of furosemide in our racehorses agrees well with previous findings $[1,2]$. In this study, horses were exposed to both treatments (controlled access to water and supramaximal treadmill exercise 24 and $4 \mathrm{~h}$ post-drug administration).

Table 1 Plasma concentration $(\mathrm{ng} / \mathrm{mL})$ of furosemide in plasma from horses treated intravenously with furosemide at $1 \mathrm{mg} / \mathrm{kg}(n=$ 4)

Time Horses treated with furosemide $24 \mathrm{~h}$ before supramaximal

(h) treadmill exercise with controlled access to water

\begin{tabular}{|c|c|c|c|c|c|c|c|c|c|}
\hline & & & & & & & & & \\
\hline & A & $\mathrm{F}$ & B & $D$ & & A & $F$ & B & $D$ \\
\hline 0 & 0 & 0 & 0 & 0 & 0 & 0 & 0 & 0 & 0 \\
\hline 0.1 & 3678 & 3666 & 3525 & 4021 & 0.1 & 3274 & 3369 & 3697 & 5532 \\
\hline 0.5 & 707 & 574 & 645 & 871 & 0.5 & 534 & 669 & 651 & 876 \\
\hline 1 & 250 & 232 & 272 & 241 & 1 & 197 & 228 & 243 & 685 \\
\hline 1.5 & 94 & 147 & 148 & 149 & 1.5 & 121 & 122 & 126 & 166 \\
\hline 3 & 54 & 131 & 142 & 111 & 3 & 83 & 87 & 92 & 53 \\
\hline 6 & ND & 113 & 117 & 61 & 6 & 63 & 57 & 64 & ND \\
\hline 9 & ND & ND & 92 & 55 & 9 & 49 & ND & 37 & ND \\
\hline 12 & ND & ND & ND & ND & & & & & \\
\hline
\end{tabular}

Time Horses treated with furosemide $4 \mathrm{~h}$ before supramaximal treadmill Time Horses treated with furosemide $4 \mathrm{~h}$ befo
(h) exercise with controlled access to water

ND Furosemide not detected or below the lower limit of quantification $(25 \mathrm{ng} / \mathrm{mL})$ of the HPLC_UV method. No furosemide was detected at later time points 

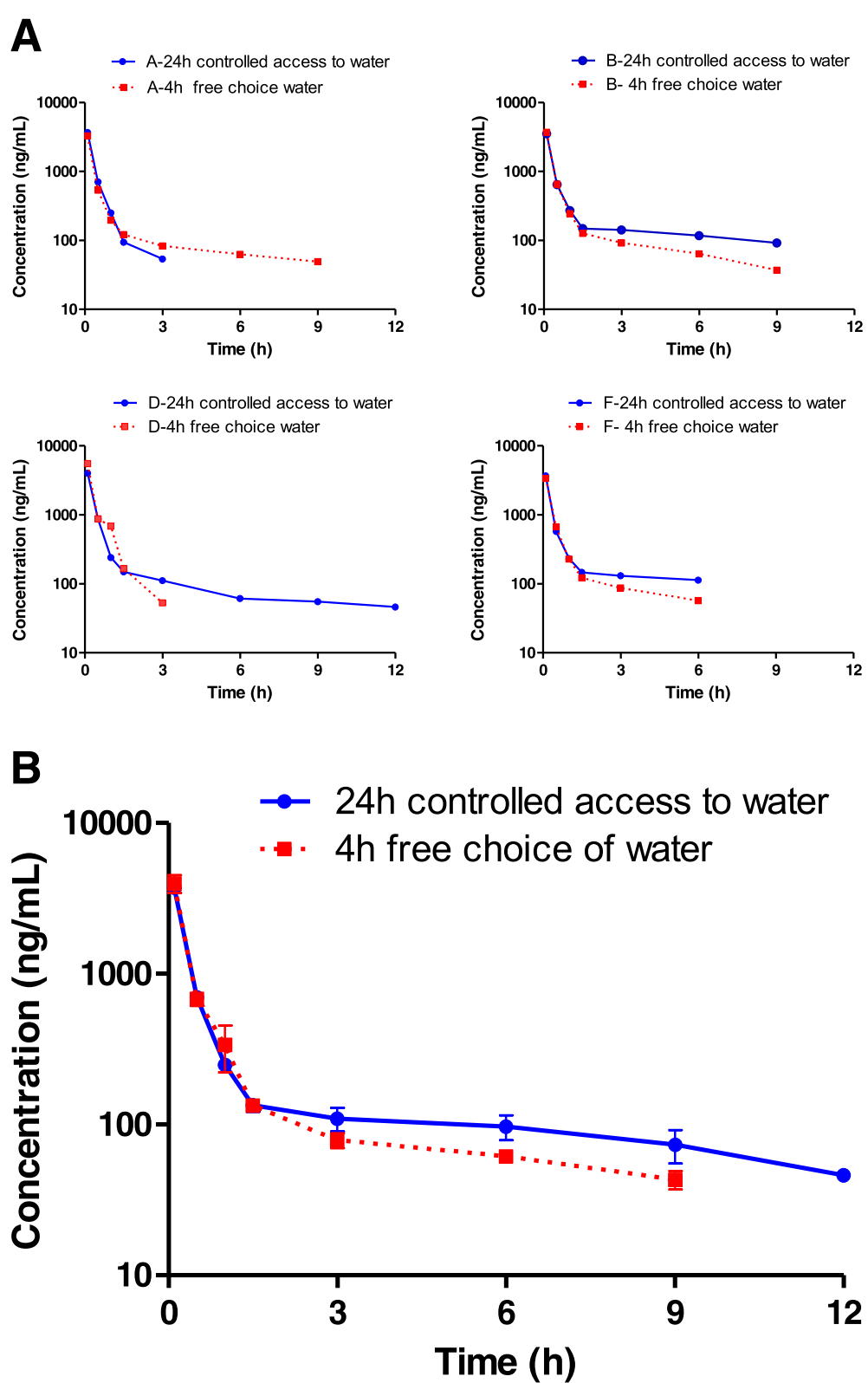

Fig. 1 Plasma concentration of furosemide vs. time in horses treated with furosemide at $1 \mathrm{mg} / \mathrm{kg}$ of body weight intravenously 24 and $4 \mathrm{~h}$ preexercise with controlled intake of water $(6 \mathrm{~mL} / \mathrm{kg}$ every $4 \mathrm{~h}$ ) with the last drink being taken $8 \mathrm{~h}$ before exercise (circle) and free choice of water until $4 \mathrm{~h}$ before exercise (square), respectively. a Each plot corresponds to an experimetnal horse (from A to D) and $\mathbf{b}$ mean ( \pm SEM) plasma concentrations $(n=4)$

One of the advantages of such an experimental design is that each horse served as its own control. Moreover, it enabled us to reduce the impact of inter-individual variability on our results. The first $3 \mathrm{~h}$ post-furosemide administration allowed us to assess the effect of water restriction on drug disposition, whereas the 3 to $24 \mathrm{~h}$ time points post-administration enabled us to compare the disposition of furosemide between exercised horses and horses exposed to the controlled water intake protocol.
The water management protocol used in this study did not exert any effect on the disposition of furosemide, as reflected in the lack of differences in the $\mathrm{AUC}_{0-3 \mathrm{~h}}$ between the two groups. This finding concurs with the results reported by Knych and colleagues [12]. This finding was unexpected, particularly when considering that furosemide has a remarkable diuretic effect during the first $3 \mathrm{~h}$ following its administration [4]. It is likely that the controlled water protocol used in this study did not result in a significant reduction in the circulating 
Table 2 Plasma pharmacokinetic parameters of furosemide in horses treated intravenously with furosemide at $1 \mathrm{mg} / \mathrm{kg}(n=4)$

\begin{tabular}{|c|c|c|c|c|c|c|c|c|c|c|c|c|}
\hline \multirow[t]{2}{*}{ Parameter } & \multicolumn{6}{|c|}{$\begin{array}{l}\text { Horses treated with furosemide } 4 \mathrm{~h} \text { before supramaximal } \\
\text { treadmill exercise }\end{array}$} & \multicolumn{6}{|c|}{$\begin{array}{l}\text { Horses treated with furosemide } 24 \mathrm{~h} \text { before supramaximal } \\
\text { treadmill exercise with controlled access to water }\end{array}$} \\
\hline & $\bar{A}$ & $\mathrm{~F}$ & B & D & Geo. Mean & $95 \% \mathrm{Cl}$ of Geo mean & $A$ & $\mathrm{~F}$ & B & D & Geo. Mean & $95 \% \mathrm{Cl}$ of Geo mean \\
\hline$a(1 / h)$ & 5.07 & 4.47 & 4.81 & N/A & 4.78 & $4.07-5.61$ & 5.2 & 5.1 & 4.8 & 4.2 & 4.9 & $4.12-5.6$ \\
\hline$\beta(1 / h)$ & 0.14 & 0.20 & 0.18 & N/A & 0.17 & $0.1-0.27$ & 0.18 & 0.07 & 0.08 & 0.11 & 0.10 & $0.05-0.20$ \\
\hline$\beta_{-} H_{L}(h)$ & 4.90 & 3.57 & 3.82 & N/A & 4.06 & $2.68-6.16$ & 3.8 & 9.3 & 8.4 & 6.0 & 6.5 & $3.40-12.4$ \\
\hline $\mathrm{A}(\mathrm{ng} / \mathrm{mL})$ & 5180 & 4990 & 5700 & N/A & 5280 & $4470-6230$ & 5200 & 5630 & 5380 & 5850 & 5510 & $5080-6000$ \\
\hline$B(n g / m L)$ & 151 & 170 & 179 & N/A & 166 & 134-206 & 167 & 172 & 190 & 157 & 171 & $151-193$ \\
\hline K10 (1/h) & 2.55 & 2.60 & 2.70 & N/A & 2.61 & $2.43-2.81$ & 2.8 & 1.7 & 1.6 & 2.8 & 2.05 & $1.38-3.09$ \\
\hline K12 (1/h) & 2.38 & 1.73 & 1.97 & N/A & 2.01 & $1.35-3.00$ & 2.2 & 3.2 & 3.0 & 1.9 & 2.52 & $1.67-3.8$ \\
\hline K21 (1/h) & 0.28 & 0.33 & 0.32 & N/A & 0.31 & $0.25-0.40$ & 0.3 & 0.2 & 0.2 & 0.2 & 0.25 & $0.18-0.35$ \\
\hline V1 (mL/kg) & 188 & 194 & 170 & N/A & 184 & $156-217$ & 173 & 164 & 180 & 166 & 170 & $160-183$ \\
\hline $\mathrm{CL}_{\text {Pred }}(\mathrm{mL} / \mathrm{h} / \mathrm{kg})$ & 442 & 444 & 402 & 356 & 409 & $347-482$ & 541 & 240 & 250 & 323 & 320 & $177-580$ \\
\hline $\operatorname{Tmax}(h)$ & 0.1 & 0.1 & 0.1 & 0.1 & 0.1 & N/A & 0.1 & 0.1 & 0.1 & 0.1 & 0.1 & N/A \\
\hline Cmax (ng/mL) & 3270 & 3370 & 3700 & 5530 & 3880 & $2630-5700$ & 3680 & 3670 & 3530 & 4020 & 3700 & $340-4060$ \\
\hline $\mathrm{CO}(\mathrm{ng} / \mathrm{mL})$ & 5150 & 5040 & 5700 & 8770 & 6000 & 3980-9050 & 5555 & 5830 & 5390 & 5900 & 5660 & $5300-6050$ \\
\hline$A \cup C_{0 \text {-inf }}\left(h^{*} n g / m L\right)$ & 1860 & 4170 & 3950 & 3130 & 3129 & $1741-5624$ & 2280 & 2260 & 2490 & 2810 & 2450 & 2086-2879 \\
\hline$A \cup C_{\text {last }}\left(h^{*} n g / m L\right)$ & 1810 & 1900 & 2050 & 2760 & 2100 & $1500-2840$ & 1775 & 2190 & 2530 & 2630 & 2250 & $1700-3000$ \\
\hline$A \cup C_{0 \_1.5 h}\left(h^{*} \mathrm{ng} / \mathrm{mL}\right)$ & 1440 & 1540 & 1650 & 2600 & 1760 & $1150-2690$ & 1664 & 1620 & 1610 & 1850 & 1680 & $1520-1800$ \\
\hline$A \cup C_{0 \_3 h}\left(h^{*} n g / m L\right)$ & 1600 & 1700 & 1820 & 2760 & 1920 & $1300-2850$ & 1775 & 1820 & 1830 & 2050 & 1870 & $1690-2060$ \\
\hline
\end{tabular}

$A$ Distribution intercept, $a$ Distribution rate constant, $B$ Post-distribution phase intercept, $\beta$ Elimination rate constant, $C L$ Systemic drug clearance, $k 10, k 12$, and $k 21$ Microdistribution rate constants, N/A No applicable -- for this horse, compartmental modeling was performed but there was no appropriate PK model fitting, AUClast Area under the concentration vs. time curve from time $0 \mathrm{~h}$ to the last sampling time, $A \cup C_{\text {inf }}$ Area under the concentration vs time curve from time $0 \mathrm{~h}$ to infinite, $A \cup C_{0-1.5 \mathrm{~h} \text { and }} A \cup C_{0-3 \mathrm{~h}}$ Partial area under the concentration vs time curve from time $0 \mathrm{~h}$ to 1.5 and $3 \mathrm{~h}$ post-drug administration

plasma volume, nor did it alter the elimination of the drug.

In contrast, examination of the plasma concentrations of furosemide $24 \mathrm{~h}$ after drug administration (Table 3) might suggest that in the horses subjected to managed water intake, the concentrations of furosemide were numerically higher than those in the horses with free access to water. The large inter-individual variability compromised the ability to detect differences, therefore, a larger number of horses should be used in further studies to confirm this observation. The effects of more restrictive controlled water intake protocols on the disposition of furosemide in horses should also be evaluated.
During the period following the first $3 \mathrm{~h}$ after furosemide administration, in 3 out of 4 horses belonging to the group of animals exercised $4 \mathrm{~h}$ after the administration of the substance, the plasma concentrations of furosemide were numerically lower (Fig. 1), probably reflecting a faster decrease in the plasma concentration of the drug. The lack of a control group (i.e., horses treated with furosemide without water restriction and not exposed to supramaximal exercise) prevented us from determining whether the difference between the groups was due to the exercise or to the effect of controlled access to water. In a study conducted by Dyke and colleagues, prolonged submaximal exercise did not alter the disposition of furosemide [1]. In addition, Knych and collaborators

Table 3 Tolerance limit and plasma concentration $(\mathrm{ng} / \mathrm{mL})$ of furosemide from Thoroughbred horses $(n=6)$ at $24 \mathrm{~h}$ after furosemide administration at $1 \mathrm{mg} / \mathrm{Kg}$ or $0.5 \mathrm{mg} / \mathrm{Kg}$ to horses with controlled access to water ( $6 \mathrm{~mL} / \mathrm{kg}$ every $4 \mathrm{~h}$ ), with the last drink being taken $8 \mathrm{~h}$ before exercise or free choice water until $4 \mathrm{~h}$ before exercise

\begin{tabular}{|c|c|c|c|c|}
\hline \multirow[t]{3}{*}{ Horse } & \multicolumn{4}{|l|}{ Treatment } \\
\hline & \multicolumn{2}{|l|}{$1 \mathrm{mg} / \mathrm{kg}$} & \multicolumn{2}{|l|}{$0.5 \mathrm{mg} / \mathrm{kg}$} \\
\hline & $\begin{array}{l}\text { Free choice water } \\
n=6\end{array}$ & $\begin{array}{l}\text { Controlled access to water } \\
n=6\end{array}$ & $\begin{array}{l}\text { Free choice water } \\
n=6\end{array}$ & $\begin{array}{l}\text { Controlled access to water } \\
n=6\end{array}$ \\
\hline Mean & 0.44 & 0.80 & 0.22 & 0.35 \\
\hline SD & 0.72 & 1.3 & 0.15 & 0.53 \\
\hline Tolerance limit & 5.0 & 9.0 & 1.20 & 3.8 \\
\hline
\end{tabular}


reported that water withholding for the $4 \mathrm{~h}$ before exercise did not alter the disposition of furosemide in horses [12]. Although unlikely, due to its relatively short duration ( $<3$ mins), the possibility that the supramaximal treadmill exercise $4 \mathrm{~h}$ after the administration of furosemide modified the subsequent disposition of furosemide cannot be completely ruled out.

In this study the plasma concentrations of furosemide were assessed for $24 \mathrm{~h}$ following the administration of the drug but, with UV detection, we were only able to detect this substance in the plasma up to $12 \mathrm{~h}$ after its administration. Even though these sample concentrations accounted for more than $80 \%$ of the $\mathrm{AUC}_{0-\infty}$, this was a limitation of the analytical method. Examination of the concentration vs. time profile of furosemide (Fig. 1) suggests that furosemide should still be detectable by LC-MS/MS $24 \mathrm{~h}$ after its administration. In fact, in a recent study, furosemide was detected in plasma up to $36 \mathrm{~h}$ after the administration of $250 \mathrm{mg} / \mathrm{kg}$ intravenously to racehorses [12]. This could be relevant if race day medication was banned and horses were dosed with furosemide $\geq 24$ h before the start of a race in jurisdictions in which the presence of any furosemide in plasma at race time was prohibited. Under these conditions racing jurisdictions would be best advised to adopt an accepted threshold for plasma furosemide rather than taking a zero tolerance stance. In order to verify this observation, we employed a more sensitive analytical technique to evaluate the concentrations of furosemide $24 \mathrm{~h}$ after its administration in samples collected from horses exposed to four treatment protocols. As expected, using a LC-MS/MS method characterized by an LOQ of $0.1 \mathrm{ng} / \mathrm{mL}$, we were also able to detect and quantify furosemide in the plasma of all horses after the administration of both $0.5 \mathrm{mg} / \mathrm{kg}$ and $1 \mathrm{mg} / \mathrm{kg}$ intravenously, thereby confirming previous findings [1].

There was substantial variability in the plasma concentration of furosemide in all treatment groups $24 \mathrm{~h}$ after its administration. It is unknown whether the plasma concentrations of this drug and the observed inter-individual variability have any biological relevance. However, it is likely that the plasma concentrations detected are pharmacologically irrelevant, at least as far as the diuretic effects of furosemide are concerned. Drawing from results published by Tobin et al., [4]. Johansson and colleagues [2] estimated that, in horses, furosemide may have a diuretic effect at plasma concentrations as low as $70 \mathrm{ng} / \mathrm{mL}$. This concentration is $>18$ times higher than the highest plasma furosemide concentration measured in our study horses $24 \mathrm{~h}$ after dosing. Using the mean and SD of furosemide plasma concentration generated and the tolerance limit criteria, we found with $99 \%$ certainty that $95 \%$ of the horses would have had a plasma concentration of furosemide below 9.0 and $3.8 \mathrm{ng} / \mathrm{mL} 24 \mathrm{~h}$ after the iv administration of 1.0 or $0.5 \mathrm{mg} / \mathrm{kg}$ furosemide, respectively (Table 3). Although the concentrations obtained in this study $24 \mathrm{~h}$ after furosemide administration are lower than the proposed minimum concentration required to exert any diuretic effect, a recent study has indicated that the urinary whole body calcium and chloride balance remain low for $72 \mathrm{~h}$ after a single IV injection of $0.5 \mathrm{mg} / \mathrm{kg}$ furosemide [17]. Therefore, it would be necessary to assess whether furosemide has any other renal or extra-renal pharmacological effects that may exert an impact on horses' athletic performance.

\section{Conclusion}

This study provides new information about furosemide disposition in Thoroughbred horses treated intravenously with $1 \mathrm{mg} / \mathrm{kg}$ furosemide 4 and $24 \mathrm{~h}$ before supramaximal treadmill exercise without and with managed access to water, respectively. Our findings are comparable to those recently published by Knych et al. [12], despite the differences in experimental designs (furosemide dose, different water restriction and exercise protocol). The similarity of the findings of these two independent studies clearly increases the robustness of the results of both studies.

Furosemide was detectable in the plasma of horses exposed to supramaximal treadmill exercise with and without controlled water intake $24 \mathrm{~h}$ after dosing. Water restriction did not exert any apparent effect on the disposition of furosemide. It remains to be determined, however, whether the attained plasma concentration of furosemide in combination with other controlled water access protocols have any direct or indirect pharmacological effect that may affect the athletic performance of the horse.

\section{Methods \\ Animals and management}

The research protocol was approved by the Washington State University Institutional Animal Care and Use Committee (ASAF \#04726).

\section{Study population}

Six horses $4-10$ years of age $(6.7 \pm 1.9$ (mean \pm SD) years) with body weights $451-547 \mathrm{~kg}(491 \pm 25 \mathrm{~kg})$, were included in the study. Horses were purchased from their former owners at the conclusion of their racing careers by the Department of Veterinary Clinical Sciences, Washington State University for inclusion oi the study. There were $2 \mathrm{fe}-$ males and 4 males of which 3 had been gelded. A full physical examination, a complete blood count and serum biochemistry evaluations were performed on each horse before enrollment in the study. Horses had a body condition of 5 (scale 1-10), as the study commenced within 2 weeks 
of their arrival from the racetrack where they had been regularly undergoing strenuous exercise in the form of fast training (i.e., breezing) and racing. Their fitness was maintained with treadmill galloping exercise 3 times per week throughout the course of the study. All horses had been diagnosed as having $\geq$ Grade 2 EIPH using post-race tracheoendoscopy. During the study, horses were keep in individual stalls fed a free choice mixture of grass and alfalfa hay plus a fortified grain supplement twice daily.

\section{Objective 1 -- experimental design}

Four of the horses were randomly allocated to two treatment sequences using a 2 sequence, 2 period crossover design. Horses allocated to treatment sequence 1 received furosemide (Furosemide, VetOne, Boise, ID) 24 h before exercise and were given water in a controlled manner, as described below. After the first treatment period, horses received furosemide $4 \mathrm{~h}$ before exercise with water withheld until after they had exercised. Horses in treatment sequence 2 , received furosemide $4 \mathrm{~h}$ before exercise, as described below. Following the first period, horses were treated with furosemide $24 \mathrm{~h}$ before exercise after which access to water was controlled. In all instances, the dose of furosemide administered was $1.0 \mathrm{mg} / \mathrm{kg}$ intravenously. This dose was selected because it has been widely studied from a pharmacological perspective, thereby facilitating comparisons between horses and with the existing literature. This would not have been possible had an absolute iv dose of $500 \mathrm{mg}$ been given to every horse. Food was withheld for the last $4 \mathrm{~h}$ before exercise. In order to avoid a carryover effect, at least 14 days elapsed ( $>10$ furosemide half-lives) between treatment periods.

\section{Water provision protocol}

In order to evaluate the potential effect of controlled water intake on the disposition of furosemide, horses receiving furosemide $24 \mathrm{~h}$ before exercise were given water at a rate of $6 \mathrm{~mL} / \mathrm{kg}$ every $4 \mathrm{~h}$ after the of furosemide, with the last drink occurring $8 \mathrm{~h}$ before exercise. Horses given furosemide $4 \mathrm{~h}$ before exercise had free choice access to water until they received furosemide, after which water was withheld until the exercise was completed.

\section{Exercise protocol}

All the horses were exercised to fatigue at the speed that had a calculated oxygen demand that was $115 \%$ of its maximum oxygen consumption $\left(\dot{\mathrm{V}}_{2}\right.$ max $)$ on a treadmill inclined at $5 \%, 4$ or $24 \mathrm{~h}$ after the administration of furosemide. The treadmill speed was calculated from the regression equation for the linear portion of the $\dot{\mathrm{VO}}_{2^{-}}$ speed relationship that was generated for each horse 4 days before commencing the study. Fatigue was defined as the point at which a horse could no longer keep pace with the treadmill despite strong verbal encouragement.

\section{Blood sampling times}

For horses in the group treated with furosemide $24 \mathrm{~h}$ before exercise, blood samples were collected immediately before dosing and $0.1,0.5,1,1.5,3,6,9,12$ and $24 \mathrm{~h}$ after dosing (pre-exercise period) and 0.1, 0.5, 1, 1.5 , and $3 \mathrm{~h}$ post-exercise. For the group of horses treated with furosemide $4 \mathrm{~h}$ prior to exercise, blood samples were collected immediately before dosing and $0.1,0.5,1,1.5,3,6,9,12$ and $24 \mathrm{~h}$ post-dosing.

Blood samples were collected into EDTA tubes and centrifuged at $1800 \times g$ for $8 \mathrm{~min}$. The plasma was separated and $200 \mu \mathrm{L}$ aliquots placed in cryovials and stored at $-80^{\circ} \mathrm{C}$ until samples were analyzed.

\section{Quantification of furosemide in plasma for evaluation of its disposition following strenuous exercise}

Analysis of furosemide in plasma samples was conducted using reversed phase HPLC. The system consisted of a 2695 separations module and a 2487 ultraviolet detector (Waters, Milford, MA). Separation was attained on a Symmetry $\mathrm{C}_{18} 3.9 \times 20 \mathrm{~mm}(5 \mu \mathrm{m})$ with a Symmetry $\mathrm{C}_{18}$ guard column. The mobile phase was a mixture of (A) $20 \mathrm{mM}$ potassium phosphate monobasic (Sigma-Aldrich St. Louis, MO) pH 7 and (B) acetonitrile (Waters, Milford, MA). The mixture was pumped at a starting gradient of $79 \% \mathrm{~A}$ and $21 \% \mathrm{~B}$ and was adjusted to $75 \% \mathrm{~A}$ and $25 \% \mathrm{~B}$ over $14 \mathrm{~min}$, and back to initial conditions over $3 \mathrm{~min}$. The drug was quantified using UV detection at $220 \mathrm{~nm}$, and the flow rate was $1.0 \mathrm{~mL} / \mathrm{min}$. Furosemide was extracted from plasma samples using a solid phase extraction method. Briefly, previously frozen plasma samples were thawed and vortexed, and $100 \mu \mathrm{L}$ of each sample was transferred to a clean test tube then $100 \mu \mathrm{L}$ of internal standard $(1 \mu \mathrm{g} / \mathrm{mL}$ torsemide $)$ was added. Two hundred microliters of acetonitrile was added, then tubes were vortexed for $10 \mathrm{~s}$ and centrifuged for $20 \mathrm{~min}(1020 \mathrm{x} \mathrm{g})$. The supernatant solution was transferred to a pre-wet Oasis MAX $1 \mathrm{cc}(30 \mathrm{mg})$ extraction column (Waters, Milford, MA). The columns were eluted with $2 \mathrm{~mL}$ of $2 \%$ formic acid in acetonitrile:methanol (60:40) and then the eluates were evaporated to dryness under a steady stream of nitrogen gas. Samples were dissolved in $250 \mu \mathrm{L}$ of mobile phase, and a $100 \mu \mathrm{L}$ aliquot of each was injected into the HPLC system.

Standard curves for plasma analysis were prepared by supplementing untreated horse plasma with furosemide (Sigma-Aldrich St. Louis, MO), which produced a linear concentration range of $25-7500 \mathrm{ng} / \mathrm{ml}$.

Average recovery was $100 \%$ for furosemide and $99 \%$ for torsemide (Sigma-Aldrich St. Louis, MO). Intra-assay variability ranged from 3.0 to $8.9 \%$ for torsemide, and from 
2.6 to $10.0 \%$ for furosemide, respectively. The lower limit of quantification for furosemide was $25 \mathrm{ng} / \mathrm{mL}$.

Estimation of pharmacokinetic parameters of furosemide Primary and secondary pharmacokinetic parameters were determined by non-compartmental analysis using Phoenix WinNonlin $^{\oplus}$ v. 7 (Certara, Princenton, NJ). Pharmacokinetic parameters included: total body (systemic) clearance (CL), area under the concentration-first moment time curve through last sample time post-dose (AUMC), elimination half-life $\left(t_{1 / 2}\right)$, observed maximal concentration (Cmax), time to maximal concentration (tmax), mean residence time (MRT), and area under the plasma concentration-time curve from $0 \mathrm{~h}$ to last sample time $\left(\mathrm{AUC}_{0 \text {-last }}\right.$ $\mathrm{h}$ ), from $0 \mathrm{~h}$ to $1.5 \mathrm{~h} \mathrm{AUC}_{0-1.5 \mathrm{~h}}$ and from 0 to $3 \mathrm{~h}$ after dosing $\left(\mathrm{AUC}_{0-3 \mathrm{~h})}\right.$. The AUCs were calculated using the linear trapezoidal rule.

\section{Objective 2 -- experimental design}

Six horses were exposed to four different combinations of furosemide administration and water intake, each of which was initiated $24 \mathrm{~h}$ before exercise. A randomized Latin square crossover design was used and in no instance was there less than 14 days between any treatment protocol. The treatments were: 1 ) furosemide at 1 $\mathrm{mg} / \mathrm{kg}$ intravenously pre-exercise with free choice access to water until $4 \mathrm{~h}$ before exercise; 2) furosemide at $1 \mathrm{mg} /$ $\mathrm{kg}$ intravenously pre-exercise with controlled access to water $(6 \mathrm{~mL} / \mathrm{kg}$ every $4 \mathrm{~h})$, with the last drink being taken $8 \mathrm{~h}$ before exercise; 3) furosemide at $0.5 \mathrm{mg} / \mathrm{kg}$ intravenously pre-exercise with free choice water until 4 $\mathrm{h}$ before exercise; and 4) furosemide at $0.5 \mathrm{mg} / \mathrm{kg}$ intravenously pre-exercise with the same controlled access water as described above.

\section{Exercise protocol}

All horses were exercised to fatigue on a treadmill at the speed that had a calculated $\dot{\mathrm{VO}}_{2}$ that was $115 \%$ of its $\dot{\mathrm{VO}}_{2}$ max as described for Objective 1 .

\section{Blood sampling and processing}

Jugular blood samples were collected into EDTA tubes $24 \mathrm{~h}$ after drug administration; i.e., immediately before exercise. Samples were promptly centrifuged at $1800 \times g$ for $8 \mathrm{~min}$. The plasma was separated and $200 \mu \mathrm{L}$ aliquots were placed into cryovials and stored at $-80^{\circ} \mathrm{C}$ until analyzed.

\section{Detection of furosemide concentration in plasma $24 \mathrm{~h}$ after the administration of furosemide using four different treatment protocols}

In order to determine the concentration of furosemide in equine plasma $24 \mathrm{~h}$ after administering the drug, samples were submitted to LGC Science (LGC Science, Inc.,
Lexington, KY), because their analytical methods were characterized by a lower limit of quantification than the one used to evaluate the pharmacokinetics of furosemide (see Objective 1).

Analysis of furosemide in plasma samples was conducted using a validated liquid chromatography-mass spectrometric method (LC-MS/MS) under electrospray ionization conditions using a triple quadrupole mass spectrometer in negative ionization mode [18]. The system consisted of an Accela $1250^{\text {тм }}$ (Thermo Fisher, Waltham, MA) separations module and TSQ Vantage ${ }^{\mathrm{TM}}$ mass detector (Thermo Fisher, Waltham, MA). Separation was attained on a $75 \mathrm{~mm} \times 2.1 \mathrm{~mm}, 2.7 \mu \mathrm{m}$ Ascentis Express ${ }^{\mathrm{Tm}}$ (Supelco Sigma-Aldrich St. Louis, MO) and $5 \mathrm{~mm} \times 2.1$ $\mathrm{mm}, 2.7 \mu \mathrm{m}$ Ascentis Express ${ }^{\mathrm{TM}}$ guard column (Supelco, (Sigma-Aldrich St. Louis, MO).

The selected reaction monitoring (SRM) transition used to quantify furosemide was $\mathrm{m} / \mathrm{z} 331>\mathrm{m} / \mathrm{z} 207$ whereas, the SRM transitions used to identify furosemide were $\mathrm{m} / \mathrm{z} 331>\mathrm{m} / \mathrm{z} 287$ and $\mathrm{m} / \mathrm{z} 331>\mathrm{m} / \mathrm{z} 128$. Similar transitions were used to monitor the internal standard (furosemide- $\mathrm{d}_{5}$ ).

Furosemide and the internal standard were extracted using reversed-phase solid phase extraction of a proprietary water-wettable polymer (Cerex ${ }^{\circ}$ WWP, 96, 1$\mathrm{mL}$ columns in $\mathrm{RCH}, 20 \mathrm{mg}$ cartridges, SPEware Corporation, Seestrasse Männedorf) by the following procedure. The cartridges were sequentially conditioned with $0.5 \mathrm{~mL}$ of methanol and $0.5 \mathrm{~mL}$ of water. Plasma samples were then loaded onto the cartridges and allowed to flow through at a rate of $1-2 \mathrm{~mL} / \mathrm{min}$ The cartridges were washed with $0.5 \mathrm{~mL}$ of water: methanol $(80: 20, \mathrm{v} / \mathrm{v})$ and the pressure was increased briefly to expel any remaining solvent in the solvent bed. The analytes were then eluted from the columns with two $500 \mu \mathrm{L}$ aliquots of methanol. The pressure was increased briefly after each elution to expel any remaining solvent in the solvent bed. The eluates evaporated under nitrogen gas. The residues were then dissolved in $100 \mu \mathrm{L}$ of water:methanol (80:20, v/v), vortex-mixed to assure dissolution, and the resulting solutions were transferred to glass autosampler vials for LC-MS/MS analysis.

Calibrators were prepared from negative control plasma and working standard solutions of furosemide in methanol. The calibrators were prepared in $0.5 \mathrm{~mL}$ of plasma each at concentrations of 0, 100, 200, 500, 1000, 2000, 5000, 7500, and $10000 \mathrm{pg} / \mathrm{mL}$ of plasma.

The method was characterized by a lower limit of quantification (LLOQ) of $0.1 \mathrm{ng} / \mathrm{mL}$ and acceptable accuracy and precision throughout the calibration range of $0.1 \mathrm{ng} / \mathrm{mL}$ to $10 \mathrm{ng} / \mathrm{mL}$. Bias was insignificant, and the relative standard deviation of the inter-batch precision of the method at $1 \mathrm{ng} / \mathrm{mL}$ was $5.1 \%$. 


\section{Pharmacokinetics analysis}

Compartmental and non-compartmental analyses were performed as implemented by Phoenix WinNonlin ${ }^{\circ}$ v. 7 (Certara, Princeton, NJ). For compartmental analysis, we implemented a standard 2-stage approach (Gabrielsson and Weiner 2016). Compartmental analysis was performed with a weighting factor of $1 /$ (observed $Y$ ), where $\mathrm{Y}$ was the plasma concentration. The experimental data were modelled using a 2 compartmental model. The compartmental structure was defined by standard diagnostic tools including: standard errors of the estimates, correlation matrix, and residual plots, $\mathrm{F}$ test, Akaike's information criterion and Schwarz criteria.

For the 2-compartment biexponential analysis used for the data, the corresponding equation was: $\mathrm{C}=\mathrm{Ae}^{-\alpha \mathrm{t}}+\mathrm{Be}^{-\beta \mathrm{t}}$, where $C$ is the plasma drug concentration at time $t, A$ and $B$ are the $y$-axis intercepts for the initial and terminal phases of the curve, respectively, and $\alpha$ and $\beta$ are the slopes of the initial and terminal phases of the curve, respectively.

Several primary and secondary pharmacokinetic parameters including total body (systemic) clearance, area under the plasma concentration-time curve from $0 \mathrm{~h}$ to last sample time and from $0 \mathrm{~h}$ to infinity after dosing, area under the concentration-first moment time curve through last sample time post-dose, elimination half-life, maximal concentration, time of maximal concentration, and rate constant of elimination were estimated. The $\mathrm{AUC}_{0-1.5}, \mathrm{AUC}_{0-3}$ and $\mathrm{AUC}_{0-\text { last }}$ were calculated by the linear trapezoidal rule. Other compartmental pharmacokinetic parameters were calculated according to formulae described elsewhere [19]. The pharmacokinetic parameters were reported as geometric mean and its 95\% confidence interval.

\section{Statistical analysis}

Descriptive statistics were used to assess the data. Normality of the distribution of the pharmacokinetic parameters was assessed using the Shapiro-Wilk test (significance level $p \leq 0.05$ ). The geometric means of clearance, $\mathrm{AUC}_{0-1.5 \mathrm{~h}}, \mathrm{AUC}_{0-3 \mathrm{~h}}$ and $\mathrm{AUC}_{0 \text {-last }} \mathrm{h}$ (objective 1) of each group were compared statistically using the Student t-test. The level of significance for the statistical comparisons was set at $p \leq 0.05$. Parameters are reported using 3 significant digits.

Using the mean and standard deviation of the plasma concentration of furosemide at $24 \mathrm{~h}$ post-drug administration of each group, we estimated the upper tolerance intervals for $95 \%$ of the population with $99 \%$ certainty using standard methods (http://statpages.org/tolintvl.html) (NIST/Sematech Handbook Section 7.2.6.3).

\section{Abbreviations}

EIPH: Exercise-induced pulmonary hemorrhage; HPLC-UV: High performance liquid chromatography with ultra-violet detection; LC-MS/MS: Liquid chromatography with ultra-violet detection with tandem mass spectrometry detection; LLOQ: Lower limit of quantification

\section{Acknowledgements}

The invaluable assistance of Elena Kremer, Sarah Eichler, Jenna Moline, Nick Hall, Gabriela Baers, Jacob Ceniceros, Loren Normandeau, Karen Hoagland, Dominic Eickert, Zena Hemmen, Jared Hardaway, Janaki Swanson, Josh Packer and Kade Grende is gratefully acknowledged. This work was performed at Washington State University, PO Box 646610, Pullman, WA.

\section{Authors' contributions}

NFV and WMB designed the study. CML and WMB did the in vivo experiments; RAS quantified furosemide in plasma. BWM and VNF interpreted the data and wrote the manuscript. All authors read and approved the final manuscript.

\section{Funding}

This study was funded in part by the Grayson-Jockey Club Research Foundation, the AAEP Foundation, Churchill Downs, Del Mar Thoroughbred Club, Keeneland Racetrack, Kentucky Downs, The Stronach Group, New York Racing Association, Oak Tree Racing Association, Oaklawn Racetrack, the

Thoroughbred Horseman's Association, and the Washington State University College of Veterinary Medicine Equine Research Program.

None of these entities played a role in the design of the study, the collection, analysis, and interpretation of the data; or in writing the manuscript.

\section{Availability of data and materials}

The datasets used and/or analysed during the current study are available from the corresponding author on reasonable request.

\section{Ethics approval and consent to participate}

This work was approved by the Institutional Animal Care and Use Committee at Washington State University.

\section{Consent for publication}

Not applicable.

\section{Competing interests}

Dr. Bayly is a former member of the Board of Directors of the American Association of Equine Practitioners. Dr. Bayly is currently a member of the Grayson-Jockey Club Research Advisory Committee, but was not at the time of funding. The other authors have no conflicts of interest.

\section{Author details}

${ }^{1}$ Program in Individualized Medicine, Department of Veterinary Clinical Sciences, Washington State University, Pullman, WA 99164-6610, USA.

2Department of Veterinary Clinical Sciences, Washington State University, PO Box 646610, Pullman, WA 99164-6610, USA. ${ }^{3}$ LGC Science Inc., Lexington, KY 40509, USA.

Received: 9 April 2019 Accepted: 22 July 2019

Published online: 02 August 2019

\section{References}

1. Dyke TM, Hinchcliff KW, Sams RA, McKeever KH, Muir WW. The effects of submaximal exercise on the pharmacokinetics of furosemide in horses. J Vet Pharmacol Ther. 1996;19:164-6.

2. Johansson AM, Gardner SY, Levine JF, Papich MG, Lafevers DH, Goldman RB, Sheets MK, Atkins CE. Pharmacokinetics and pharmacodynamics of furosemide after oral administration to horses. J Vet Intern Med. 2004;18:739-43.

3. Dyke TM, Sams RA, Hinchcliff KW. Intensity-dependent effects of acute submaximal exercise on the pharmacokinetics of bromsulphthalein in horses. Am J Vet Res. 1998:59:1481-7.

4. Tobin T, Roberts B, Swerczek TW, et al. The pharmacology of furosemide in the horse. III. Dose and time response relationships, effects of repeated dosing and performance effects. J Equine Med Surg. 1978;2:216-26.

5. Jaggard G. Racing problems in the U.S.A. Br J Sports Med. 1976;10:159-62.

6. Pascoe JR, Ferraro GL, Cannon JH, Arthur RM, Wheat JD. Exercise-induced pulmonary hemorrhage in racing thoroughbreds: a preliminary study. Am J Vet Res. 1981;42:703-7. 
7. Hinchcliff KW, Morley PS, Guthrie AJ. Efficacy of furosemide for prevention of exercise-induced pulmonary hemorrhage in thoroughbred racehorses. J Am Vet Med Assoc. 2009;235:76-82.

8. Sullivan S, Hinchcliff K. Update on exercise-induced pulmonary hemorrhage. Vet Clin North Am Equine Pract. 2015;31:187-98.

9. Hinchcliff KW, Couetil LL, Knight PK, Morley PS, Robinson NE, Sweeney CR, van Erck E. Exercise-induced pulmonary hemorrhage in horses: American College of Veterinary Internal Medicine consensus statement. J Vet Int Med. 2015;29:743-58

10. Marlin DJ. Injury to the equine respiratory system associated with exercise. Havemeyer Foundation Monograph Series, vol. 15; 2004. p. 63-8.

11. Muir WW, Kohn CW, Sams R. Effects of furosemide on plasma volume and extracellular fluid volume in horses. Am J Vet Res. 1978;39:1688-91.

12. Knych HK, Vale A, Wilson WD, Kass PH, Arthur RM, Jones JH. Pharmacokinetics of furosemide administered 4 and $24 \mathrm{~h}$ prior to high-speed exercise in horses. J Vet Pharmacol Ther. 2018;41:224-9.

13. Schott HC, Hodgson DR, Bayly WM, Gollnick PD. Haematuria, pigmenturia and proteinuria in exercising horses. Eq Vet J. 1995;27:67-72.

14. Schott HC, Ragle CA, Bayly WM. Effects of phenylbutazone and furosemide on urinary excretory responses to high intensity exercise. Equine Vet $J$ Suppl. 1995;18:426-31.

15. Khazaeinia T, Ramsey AA, Tam YK. The effects of exercise on the pharmacokinetics of drugs. J Pharm Pharm Sci. 2000;3:292-302.

16. Persky AM, Eddington ND, Derendorf HA. Review of the effects of chronic exercise and physical fitness level on resting pharmacokinetics. Int I Clin Pharmacol Ther. 2003:41:504-16.

17. Pagan J, Waldridge B, Whitehouse C. Furosemide administration affects mineral excretion in exercised thoroughbreds. Equine Vet J. 2014;46(Suppl 46):4.

18. Sams R. Determination of serum furosemide in blood samples collected for $24 \mathrm{~h}$ after IV administration to thoroughbred horses. In: Proceedings of the 21st International Conference of Racing Analysts and Veterinarians, Montevideo, Uruguay, October 15-22nd, 2016.

19. Gabrielsson J, Weiner D. In: Gabrielsson J, Weiner D, editors Pharmacokinetic and Pharmacodynamic Data Analysis: Concepts and Applications, 5th edition. Johan Gabrielsson and Apotekarsocieteten, Swedish Pharmaceutical Society; 2016. p. 333.

\section{Publisher's Note}

Springer Nature remains neutral with regard to jurisdictional claims in published maps and institutional affiliations.

Ready to submit your research? Choose BMC and benefit from:

- fast, convenient online submission

- thorough peer review by experienced researchers in your field

- rapid publication on acceptance

- support for research data, including large and complex data types

- gold Open Access which fosters wider collaboration and increased citations

- maximum visibility for your research: over $100 \mathrm{M}$ website views per year

At $\mathrm{BMC}$, research is always in progress.

Learn more biomedcentral.com/submissions 